\title{
HIPPOCAMPAL CELL PROLIFERATION AND EPILEPTOGENESIS AFTER AUDIOGENIC KINDLING ARE NOT ACCOMPANIED BY MOSSY FIBER SPROUTING OR FLUORO-JADE STAINING
}

\author{
R. N. ROMCY-PEREIRA AND N. GARCIA-CAIRASCO* \\ University of São Paulo, Ribeirão Preto School of Medicine, Avenue \\ Bandeirantes 3900, 14049-900 Ribeirão Preto, São Paulo, Brazil
}

\begin{abstract}
Repetitive sound-induced seizures, known as audiogenic kindling (AK), gradually induce the transference of epileptic activity from brainstem to forebrain structures along with behavioral changes. The aim of our work was to correlate the behavioral changes observed during the AK with possible alterations in neuronal proliferation, cell death, hippocampal mossy fiber sprouting and in the EEG pattern of Wistar audiogenic rats, a genetically susceptible strain from our laboratory.

Susceptible and non-susceptible animals were submitted to repeated sound stimulations for 14-16 days and hippocampal mitotic activity was studied through the incorporation of bromodeoxyuridine (BrdU). Cell death and mossy fiber sprouting were assessed, respectively, by using FluoroJade and Timm staining, 2 and $\mathbf{3 2}$ days after the last kindling stimulation. In addition, we used immunofluorescent double labeling for a glial and a mitotic marker to evaluate newly born cell identity. Some animals had hippocampus and amygdala electrodes for EEG recordings.

Our results show that kindled animals with 6-11 generalized limbic seizures (class IV-V) had increased cell proliferation in the dentate gyrus when compared with animals with zero or one to three seizures. BrdU-positive cells labeled on day 2 and on day 32 were both GFAP negative. In the later group, rounded and well-defined BrdU-positive/GFAP-negative nuclei were seen in different portions of the granule cell layer. We did not observe any Fluoro-Jade or differential Timm staining in kindled animals at both killing times. However, EEG recordings showed intense epileptic activity in the hippocampus and amygdala of all animals with limbic seizures.

Therefore, our data indicate that AK-induced limbic epileptogenicity is able to increase the hippocampal mitotic rate, even though it does not seem to promote neuronal death or mossy fiber sprouting in the supragranular layer of the dentate gyrus. @ 2003 IBRO. Published by Elsevier Science Ltd. All rights reserved.
\end{abstract}

Key words: limbic seizures, cell proliferation, hippocampus, amygdala, EEG, rat.

${ }^{*}$ Corresponding author. Tel: +55-16-602-3330; fax: +55-16-6330017.

E-mail address: ngcairas@fmrp.usp.br (N. Garcia-Cairasco).

Abbreviations: AK, audiogenic kindling; BDNF, brain derived neural factor; BrdU, bromodeoxyuridine; DG, dentate gyrus; EEG, electroencephalogram; GCL, granule cell layer; GFAP, glial fibrillary acidic protein; GLS, generalized limbic seizures; NGF, neural growth factor; NMDA, N-methyl-D-aspartate; NT-3, neurotrophin 3; SE, status epilepticus; SPL, sound pressure level; TCV, tonic-clonic episodes; WAR, Wistar audiogenic rat.
Audiogenic seizures are generalized tonic-clonic convulsions induced by high-intensity sound stimulation that can be elicited in genetically susceptible animals, such as the Wistar audiogenic rat (WAR) strain maintained in our laboratory (Doretto et al., 2003). These seizures are generated in brainstem nuclei (Kesner, 1966; Garcia-Cairasco, 2002) and when chronically evoked, promote the appearance of limbic behaviors, which are associated to forebrain neuronal activation of the cortex, amygdala and hippocampus (Marescaux et al., 1987; Naritoku et al., 1992; Simler et al., 1999; Moraes et al., 2000).

Recent data have shown that the appearance of limbic behaviors during this forebrain recruitment depends on the amygdala activation and that audiogenic kindling (AK) potentiates a subsequent hippocampal or amygdalar electrical kindling (Hirsh et al., 1994, 1997). It indicates the occurrence of an indirect sensitization of the hippocampus and amygdala by the repeated sound stimulations. Electroencephalogram (EEG) studies have also demonstrated the transference of paroxysmal discharges from the inferior colliculus and then to cortex and amygdala (Moraes et al., 2000), as well as a progressive nuclear labeling of c-Fos protein in mesencephalic, diencephalic and telencephalic nuclei at different AK stages (Simler et al., 1994, 1999; Clough et al., 1997). In this case, c-Fos labeling was first observed occurring in the amygdala and then, in the hippocampus during kindling.

Despite several reports on the cellular responses induced by kainate (Ben-Ari, 1985), pilocarpine (Covolan and Mello, 2000) and amygdala kindled seizures (Sutula, 1991), very few studies have been done concerning the plastic changes following AK. In one of these studies, Garcia-Cairasco et al. (1996) showed that audiogenic kindled animals had a more intense Timm staining (specific for glutamatergic terminals containing zinc) in the basolateral amygdala, perirhinal and piriform cortices, but not in the hippocampus, when compared with non-seizing, sound-stimulated animals. It indicated that repeated audiogenic seizures could induce synaptic changes in certain limbic areas involved in the development of the characteristic myoclonus and rearing behaviors observed during the AK. Furthermore, extracellular unit recordings in the central nucleus of the inferior colliculus and medial geniculate body showed an increased number of acoustically evoked action potentials after AK (N'Gouemo and Faingold, 1996, 1997), suggesting a kindling-induced sensitization of this midbrain-forebrain pathway, perhaps related to the onset of limbic seizures. Finally, preliminary results have also suggested that AK is able to induce an increase of cell 
proliferation in the hippocampus of rats undergoing limbic seizures (Pereira and Garcia-Cairasco, 2000), as observed in the granule cell layer (GCL) of the dentate gyrus (DG) in different epilepsy models (Bengzon et al., 1997; Parent et al., 1997, 1998; Scott et al., 2000).

In order to get a more integrated analysis of the AK process, our work focused on the evaluation of hippocampal-cell proliferation, neuronal degeneration and mossy fiber sprouting responses following different patterns of AK seizures in susceptible animals. Electroencephalographic monitoring was used to correlate the above-mentioned morphological changes with neuronal excitability following recruitment of the forebrain.

\section{EXPERIMENTAL PROCEDURES}

\section{Animals}

A total of 12 Wistar (non-susceptible, R) male rats and 47 adult male WARs (5-9 months old) were used in the following experiments. WARs were derived from the Wistar strain of albino rats by brother-sister matings and have been selected for audiogenic seizure sensitivity along 27 generations (Doretto et al., 2003). The animals were provided by the main breeding stock of the Ribeirão Preto School of Medicine and by the Vivarium of the Physiology Department. All experimental procedures were performed according to the Brazilian Society for Neuroscience and Behavior Regulations for Animal Experimentation and all efforts were made in order to minimize animal suffering.

\section{Experiment 1}

In this experiment, we used 16 adult male WARs kept four/cage at $24{ }^{\circ} \mathrm{C}$ in a 12-h light/dark cycle (lights on at $0700 \mathrm{~h}$ ) with free access to food and water. They were submitted to AK and their tissues processed for bromodeoxyuridine (BrdU) incorporation and Fluoro-Jade histochemistry.

\section{Experiment 2}

Twelve adult male Wistar non-susceptible rats $(R)$ and 31 WARs were used in the following experiment. They were submitted to AK and had hippocampal and amygdalar EEGs simultaneously recorded during all kindling sessions. Subsequently, their tissues were processed for BrdU immunohistochemistry and BrdU/GFAP immunofluorescent double labeling, Fluoro-Jade and Neo-Timm histochemistry.

\section{Audiogenic test}

As the audiogenic trait is not present in $100 \%$ of the WARs and, eventually, some non-susceptible rats are sound sensitive, we tested all animals for sound-induced seizures before starting the AK. The audiogenic test consisted of exposing the animals to a high-intensity sound, three times in 5 days by using a recorded doorbell at $110 \mathrm{~dB}$ SPL, in an acoustically isolated chamber (1 stimulus/day; every other day; at the same daytime, 1600-1800 h). Behavioral evaluations were done throughout the tests by the assignment of mesencephalic and limbic indexes to each animal (Racine, 1972; Garcia-Cairasco et al., 1996). In each stimulus, the sound was turned off either after a tonic seizure or $1 \mathrm{~min}$ after its presentation.

\section{AK after the audiogenic test}

The rats were kept in their home cages and handled for at least 1 week before starting the AK. The AK protocol consisted of $1 \mathrm{~min}$ of habituation inside the chamber (PRE) followed by sound presentation for a maximum of $1 \mathrm{~min}$ or until a tonic seizure was observed (SOUND). After turning off the sound, the animals were observed for an additional period of at least $1 \mathrm{~min}$ (POST). Animals were acoustically stimulated twice a day (at 0800-1000 h and 1600-1800 h) during 14 days (28 stimulations; experiment 1 ) or 16 days (32 stimulations; experiment 2 ) with the same intensity and sound presentation criteria as for the audiogenic test. Behavioral evaluations were done during all the experiments and limbic behaviors observed during kindling were ranked using the Racine scale: I, orofacial automatisms; II, head myoclonus; III, forelimb myoclonus; IV, rearing; V, rearing followed by loss of balance and falling (Racine, 1972). Class IV and V seizures were considered as generalized limbic seizures (GLS) and were used to group WARs in experiments 1 and 2.

\section{Electrode implantation and EEG}

Stainless steel electrodes $(\phi=0.125 \mathrm{~mm})$ were implanted under deep anesthesia (ketamine hydrocloride:xylazine, $14: 1 \mathrm{mg} / \mathrm{kg}$, Agener União, São Paulo, Brazil and Bayer, São Paulo, Brazil; respectively) using stereotaxic coordinates for the left basolateral complex of amygdala $(-6.3 \mathrm{~mm}$ posterior to bregma; $4.5 \mathrm{~mm}$ lateral to midline; $-4.5 \mathrm{~mm}$ ventral to dura) and the left DG (-2.0 $\mathrm{mm}$ posterior to bregma; $4.7 \mathrm{~mm}$ lateral to midline; $-7.1 \mathrm{~mm}$ ventral to dura; Paxinos and Watson, 1997). A screw was implanted in the frontal bone and served as our reference electrode. Animals were kept in individual cages and allowed to recover for 5 days during which they were handled to reduce stress. Video-EEGs were daily recorded during the 32-stimulation protocol of the AK using a video camera and an EEG acquisition system connected to a personal computer. The sound stimulation apparatus triggered all the EEG recordings. EEGs were amplified, digitized (Signal conditioner: CyberAmp 320, Axon Instruments, CA, USA; A/D converter: Biopac Systems Inc., MP100, San Francisco, CA, USA) and finally, stored in a microcomputer using the Acknowledge software package (Biopac Systems Inc.) for off-line analysis. Recording parameters used: sampling rate, $500 \mathrm{~Hz}$; amplification, 1,000×; filtering $0.1 \mathrm{~Hz}-1 \mathrm{kHz}$. Off-line band-pass filtering $(1-50 \mathrm{~Hz})$ was applied to all EEGs before analysis. In addition, a source-follower circuit using field effect transistors was used in the recording cable in order to reduce movement artifacts (Moraes et al., 2000). During every kindling session, EEG was recorded for at least $1 \mathrm{~min}$ during PRE (baseline), 1 min during SOUND (seizure) and 2 min during POST (post-ictal) phases. Control (sham-stimulated) animals were submitted to the same experimental conditions, but the sound was kept off. Finally, the rats were assigned to four groups: $R$ (sound-stimulated nonsusceptible; $n=06$ ), R-sham (sham-stimulated non-susceptible; $n=06$ ); WAR (sound-stimulated WARs; $n=21$ ) and WAR-sham (sham-stimulated WARs; $n=10$ ).

\section{BrdU injections and tissue processing}

Following the last sound stimulation, all animals received four BrdU injections (Sigma, St. Louis, MO, USA; $50 \mathrm{mg} / \mathrm{kg}$, i.p. dissolved in $\mathrm{NaCl} 150 \mathrm{mM}) 6 \mathrm{~h}$ apart each other. Animals in experiment 1 were deeply anesthetized and perfused $24 \mathrm{~h}$ after the last BrdU injection. Animals in experiment 2 were perfused 1 or 30 days after their last injection, corresponding to 2 and 32 days after their last sound stimulation, respectively: WAR-1d sham, WAR$30 \mathrm{~d}$ sham, WAR-1d and WAR-30d. R rats were perfused 1 day after the final BrdU injection (i.e. 2 days after their last sound stimulation). Briefly, the rats were deeply anesthetized and perfused with $\mathrm{NaCl} 150 \mathrm{mM}(100 \mathrm{ml})$ and $4 \%$ paraformaldehyde in PBS $100 \mathrm{mM} \mathrm{pH} 7.4(500 \mathrm{ml})$. Rats from experiment 2 were additionally perfused with $0.1 \% \mathrm{Na}_{2} \mathrm{~S}$ in Millonig's buffer: $120 \mathrm{mM}$ phosphate buffer/ $0.2 \mathrm{mM} \mathrm{CaCl}_{2}(250 \mathrm{ml})$ after saline. The brains were removed, post-fixed in the aldehyde solution and cryopro- 
tected in $30 \%$ sucrose in PBS $100 \mathrm{mM} \mathrm{pH} 7.4$ at $4{ }^{\circ} \mathrm{C}$. They were then frozen in isopentane/dry ice and sectioned. Cryostat coronal sections were obtained from six different areas along the anteroposterior axis (I: $-2.6 \mathrm{~mm}$; II: $-3.1 \mathrm{~mm}$; III: $-3.6 \mathrm{~mm}$; IV: $-4.1 \mathrm{~mm}$; V: $-4.6 \mathrm{~mm}$; Vl: $-5.1 \mathrm{~mm}$ : in reference to bregma; Paxinos and Watson, 1997). Sixteen-micrometer sections were mounted on slides and $40 \mu \mathrm{m}$ sections were collected in cryoprotection solution $(30 \%$ ethyleneglycol $+30 \%$ sucrose in PBS $100 \mathrm{mM} \mathrm{pH} \mathrm{7.4)} \mathrm{and} \mathrm{stored} \mathrm{at}-20^{\circ} \mathrm{C}$.

\section{BrdU immunohistochemistry}

We analyzed the hippocampal mitotic activity in animals following different patterns of seizures using immunohistochemistry for BrdU, a thymidine analog that is incorporated by dividing cells throughout the S-phase of the cell cycle (Nowakowski et al., 1989). In experiment 1 , the animals were killed $24 \mathrm{~h}$ after the last BrdU administration and they were used for cell proliferation studies. In experiment 2 , on the other hand, BrdU-positive nuclei were examined 30 days after the last BrdU injection, in order to evaluate the identity and permanence of the newly generated cells in the tissue. Nuclear BrdU incorporation was immunohistochemically detected using a commercially available kit (BrdU staining kit, Oncogene, Boston, MA, USA; HCS-24). Briefly, the slides containing $16 \mu \mathrm{m}$ sections were incubated in $3 \% \mathrm{H}_{2} \mathrm{O}_{2}$ in $100 \%$ methanol for $30 \mathrm{~min}$, rinsed in PBS $10 \mathrm{mM} \mathrm{pH} 7.4$ (3×, $2 \mathrm{~min})$ followed by PBS/glycine $0.1 \mathrm{M} \mathrm{pH} 7.4$ incubation for $5 \mathrm{~min}$. After washing in PBS $(2 \times, 2 \mathrm{~min})$, the sections were partially digested with $0.125 \%$ trypsin for $15 \mathrm{~min}$, rinsed in distilled water (3×, $2 \mathrm{~min})$, incubated in denaturing solution for $30 \mathrm{~min}$ and washed in PBS $(3 \times, 2 \mathrm{~min})$. Sections were incubated in PBS/2\% BSA solution for $1 \mathrm{~h}$, and then for $12 \mathrm{~h}$, in the biotinylated anti-BrdU antibody solution (BrdU kit). Following several rinses in PBS (6×, 2 min), they were incubated with the avidin-biotin-peroxidase complex (ABC kit, Vector Laboratories, Burlingame, CA, USA) for $30 \mathrm{~min}$, re-washed in PBS $(6 \times, 2 \mathrm{~min})$ and then, reacted for $2 \mathrm{~min}$ with the $\mathrm{DAB}$ solution from the BrdU kit. All reactions were done at $25^{\circ} \mathrm{C}$.

\section{Immunofluorescence}

In order to investigate the identity of the BrdU-labeled cells in the DG, we used immunofluorescent double labeling employing antiBrdU (mitotic marker) and anti-GFAP (astroglial marker) antibodies. Additionally, literature data on the cellular neuroanatomy of the DG also helped us to evaluate the labeled cells (Amaral and Witter, 1994). Sections $(40 \mu \mathrm{m})$ were washed in PBS $10 \mathrm{mM} \mathrm{pH}$ 7.4 ( $3 \times, 5 \mathrm{~min}), \mathrm{PBS} / \mathrm{glycine} 0.1 \mathrm{M}(2 \mathrm{~min})$, rinsed in PBS $(2 \times, 2$ $\mathrm{min}$ ) and then incubated in $0.1 \%$ trypsin at $37^{\circ} \mathrm{C}(15 \mathrm{~min})$. After rinses in PBS $(3 \times, 2 \mathrm{~min})$, DNA denaturation was obtained by incubating the sections in $\mathrm{HCl} 2 \mathrm{~N}$, pre-warmed at $37^{\circ} \mathrm{C}(30 \mathrm{~min})$. It was followed by washes in PBS $(3 \times, 2 \mathrm{~min})$ and incubation with blocking solution (PBS/0.3\% Triton X-100/4\% BSA) for $4 \mathrm{~h}$. An antibody cocktail (mouse anti-BrdU, 1:300+rabbit anti-GFAP, 1:500, Calbiochem, Temecula, CA, USA) was used to double label GFAP- and BrdU-positive cell bodies, for $14 \mathrm{~h}$ at $25^{\circ} \mathrm{C}$. Following several washes in PBS $(6 \times, 5 \mathrm{~min})$, the sections were sequentially incubated with Alexa 488 conjugated anti-mouse (1: 600 , Molecular Probes, Eugene, OR, USA) and Texas Red conjugated anti-rabbit (1:1000, Molecular Probes) antibodies. Following, they were washed in PBS $(6 \times, 5 \mathrm{~min})$, incubated in $0.05 \%$ Hoechst 33342 (Molecular Probes) solution in Tris-HCl $50 \mathrm{mM} \mathrm{pH}$ 7.4, re-washed in PBS $(6 \times, 5 \mathrm{~min})$ and then mounted on slides using Fluoromount $\mathrm{G}$ (Electron Microscopy Sciences, Washington, PA, USA).

\section{Fluoro-Jade staining}

Fluoro-Jade (Histo-Chem Inc., Jefferson, AR, USA) is a fluorescein derivative that has been suggested to specifically stain de- generating neurons (Schmued et al., 1997). Here, it was used to look for neuronal death associated with the AK seizures. Before starting the staining protocol, the slides were dried for $2 \mathrm{~h}$ at $37^{\circ} \mathrm{C}$. They were then incubated in $100 \%$ ethanol for 3 min followed by $1 \mathrm{~min}$ in $70 \%$ ethanol and rinsed in distilled water for $1 \mathrm{~min}$. They were incubated in a $0.06 \%$ potassium permanganate solution with mild agitation, washed in water $(3 \times, 2 \mathrm{~min})$ and incubated in a $0.0001 \%$ Fluoro-Jade solution (in acetic acid $0.1 \%$ ) for $30 \mathrm{~min}$ at $25^{\circ} \mathrm{C}$. Finally, the slides were washed in water $(6 \times, 3 \mathrm{~min})$, dried at $37^{\circ} \mathrm{C}$ and coverslip mounted in xylene using Entellan (Merck, Rio de Janeiro, Brazil) as mounting medium. Slides coming from an animal submitted to a pilocarpine status epilepticus (90-min S.E.; perfused 15 days later) were introduced in the assay as our positive control (Turski et al., 1983).

\section{Timm staining}

The evaluation of hippocampal mossy fiber sprouting was carried out using the Timm staining which labels zinc containing glutamatergic terminals present in synapses between granule cells and CA3 pyramidal neurons (Danscher, 1981). Our main interest was to analyze the effects of isolated seizures induced by AK, on the synaptic reorganization and its potential correlation with hippocampal cell proliferation. The semi-quantitative $0-6$ scale of Jolkkonen et al. (1997) associated with a blind analysis was used to detect major silver granule precipitation in the supragranular layer of the DG, as can be observed in other limbic seizure models (Tauck and Nadler, 1985; Covolan and Mello, 2000). Brain sections mounted on slides were developed for Timm staining (Babb et al., 1991) by using the following solution: $120 \mathrm{mM}$ citrate buffer, hidroquinone $100 \mathrm{mM}$ (Sigma, St. Louis, MO, USA), arabic gum $36 \%$ (w/v, Sigma) and silver nitrate $0.08 \%$ (w/v, Cennabras, Guarulhos, São Paulo, Brazil). The reaction was carried at $21^{\circ} \mathrm{C}$ for $2 \mathrm{~h}$, under light protection and stopped by washing with tap water. The slides were dehydrated and coverslipped with Canada balsam. To avoid differences between assays and false negatives, all slides were developed in the same bath and the experiment was done in duplicate (each assay containing 37 slides).

\section{Cell counting and histological analysis}

All slides were coded and shuffled in order to provide an unbiased analysis. Bright-field images and fluorescent double-labeled sections were analyzed through Olympus BX-60 microscope coupled to an image acquisition CCD cooled camera $(750 \mathrm{~L}$, Optronics, Goleta, CA, USA) and a laser scanning confocal microscope Leica TCS_NT (Leica Microsystems, Heidelberg, Germany), respectively.

\section{Experiment 1}

We counted BrdU-labeled nuclei in a total of six sections $(16 \mu \mathrm{m})$ per animal, corresponding to three regions of the brain anteroposterior axis $(-2.6 \mathrm{~mm} ;-4.1 \mathrm{~mm}$ and $-5.1 \mathrm{~mm}$ : in reference to bregma; Paxinos and Watson, 1997), and only included those rounded and densely stained nuclear profiles observed in the sub-granular zone of the DG in both hippocampi, also considering those detected in an one-cell-body zone toward the hilus. Cell nuclei with smaller than $7 \mu \mathrm{m}$ in diameter were excluded. The counts were done with a $400 \times$ magnification.

\section{Experiment 2}

For Timm staining, mossy fiber sprouting in the supragranular layer of the DG was evaluated through the use of a semi-quantitative scale of granule distribution (Jolkkonen et al., 1997). It ranks the staining intensity and distribution of the silver granules present in the DG in a 0-6 scale: 0, no granules; 1 , sparse granules; 2 , homogeneous granule distribution; 3 , high number of granules in 
a continuous pattern or eventually in clusters; 4 , high number of granules forming a confluent layer; 5 confluent and dense layer of silver granules; 6 , granules covering the supragranular region and at least half width of the inner molecular layer. Six sections (12 hippocampi) per animal were observed in magnifications of $100 \times$ and $400 \times$. For Fluoro-Jade stain, all the sections were observed and analyzed for the presence or absence of Fluoro-Jade-positive nuclei of degenerating neurons in all the main areas of the brain (cortex, thalamus, hippocampus, amygdala, septum and substantia nigra). Sections from the pilocarpine-treated animal (positive control) were used as a reference to identify patterns of positively stained nuclei. For the immunofluorescent double labeling, we analyzed the presence, distribution and co-labeling of nuclei profiles inside the GCL and adjacent to its border, with glial (GFAP) and mitotic (BrdU) markers.

\section{Statistical analysis}

Our data were submitted to an analysis of variance followed by a multiple comparison test (Student-Newman-Keuls) considering a confidence interval of $5 \%$. The Timm quantification was submitted to an analysis of variance (Kruskal-Wallis) followed by a multiple comparison test considering a confidence interval of $5 \%$.

\section{RESULTS}

\section{Behavioral evaluation of the audiogenic test and AK}

Before starting kindling, all animals (susceptible WARs and non-susceptible Rs) were exposed to three high-intensity acoustic stimulations on alternate days, in order to test their sensitivity to audiogenic seizures. The majority (43/ $47 ; 91 \%$ ) of the WAR animals showed to be highly sensitive to sound presentation, undergoing different levels of brainstem seizures, usually observed as wild running, jumping and tonic-clonic episodes (TCV) followed by forelimb-hind-limb extensions. We did not see any behavioral limbic seizure, as often characterized by head and limb myoclonus followed by rearing and falling due to loss of balance (Racine, 1972). There was also no noticeable effect of these preliminary audiogenic tests on the semiology of seizures observed during the AK. However, with the recurrence of the AK stimulations, $50 \%$ of the susceptible animals showed a gradual combination of brainstem-dependent seizures with limbic seizures. The limbic seizures triggered by the AK often occurred after the first wild running episode and before the TCV, and were almost always followed by a second round of running and jumping episodes. Animals with no limbic recruitment had only brainstem-related behaviors throughout the AK. In contrast, non-susceptible animals were free of any type of seizures both during the audiogenic test and during the kindling, being considered resistant. In experiment 1 (WARs, $n=16$ ), $87 \%$ of all animals had at least 20 TCV and $81 \%$ underwent limbic seizures in 28 kindling episodes, indicating a very homogeneous group with regard to audiogenic susceptibility and incidence of limbic seizures. The average number of TCV and forelimb extension per rat was $15.6 \pm 5.0$ and $8.9 \pm 6.6$ (mean \pm S.D.), respectively. Besides, GLS were experienced by $56 \%$ of the rats, of which $25 \%$ had at least six episodes. In experiment 2 (12 nonsusceptible and 31 WARs: 21 sound-stimulated, 10 shamstimulated), $45 \%$ of the sound-stimulated WARs had at least $20 \mathrm{TCV}$ and $57 \%$ underwent limbic seizures in 32 kindling episodes. The average number of TCV and forelimb extension per rat was $15.5 \pm 9.2$ and $11.4 \pm 9.1$ (mean \pm S.D.), respectively. Although the fraction of animals undergoing GLS was lower than in experiment 1 (30\% compared with $56 \%$ ), $25 \%$ of the animals showed more than six GLS episodes during AK. In addition, we observed that their first limbic seizures were evenly distributed between class II (50\%) and III (42\%), with progressive appearance of class IV and V seizures. The animals were grouped according to the number of GLS experienced during the AK for the subsequent analysis: animals with six to $11 \mathrm{GLS}$, animals with one to three GLS and animals without GLS.

\section{Cell proliferation after limbic seizures}

Fig. 1 shows the quantification of the BrdU-positive nuclei stained in the DG from animals with zero, one to three and six to 11 class IV-V seizures. Clusters of positively stained nuclei were most frequently observed in the subgranular zone of the DG (Figs. 1C, 2), but in rare occasions, they were also seen in the hilus. In fact, it is in accordance with the described localization of cell progenitors in the adult hippocampus (Gould and Cameron, 1996), where the subgranular zone can be seen as a source of newborn granule cells to the adult DG. Cell quantification showed an increased number of BrdU-positive nuclei in the DG of animals with six to 11 when compared with animals with zero or one to three class IV-V seizures (Fig. 1D). No differences were detected between the zero and one to three class IV-V groups. Two different patterns of staining were observed in the GCL of animals with six to 11 class IV-V seizures. Nuclei with a dense and homogeneous labeling were present in the subgranular zone associated with nuclei having scattered patches of stained chromatin, perhaps pyknotic cells (Fig. 2). In fact, cell death and proliferation has already been shown to coexist in a tissue of high plasticity rate, as the hippocampus, following seizures (Bengzon et al., 1997). As a high proliferation rate does not necessarily mean the survival and incorporation of the newly generated cells in the DG, we investigated hippocampal-dividing cells 30 days after BrdU administration, time necessary for dentate proliferating cells to migrate and differentiate in granule neurons. We also compared them with cells labeled 1 day after BrdU injection. Fig. 3 shows a BrdU/GFAP double-labeling immunofluorescence of the DG, 1 day after the last BrdU injection. The BrdUpositive nuclei, stained in green, were localized in the subgranular zone and did not co-localize with the glial marker. It was possible to visualize glial processes going through the GCL, near the BrdU-stained cluster of nuclei. In Fig. 4, 30 days after the BrdU incorporation, we could see BrdU-positive nuclei with rounded morphology and sizes around 10-15 $\mu \mathrm{m}$ in diameter. These nuclei could be found in different portions of the GCL (Fig. 4A, B) and possibly originated from subgranular migrating cells as no BrdU-labeled cell was found in the upper rows of the CGL, 1 day after BrdU. Besides, the BrdU-labeled nuclei observed in the lower row of the GCL 30 days after BrdU 


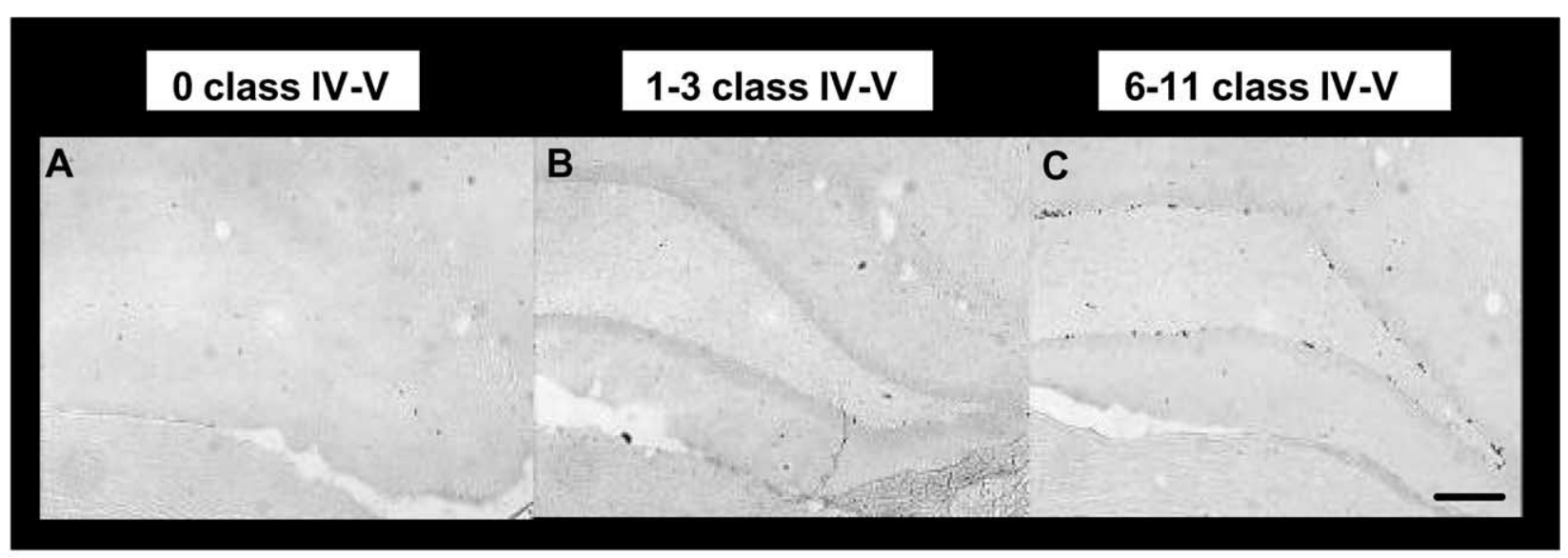

D

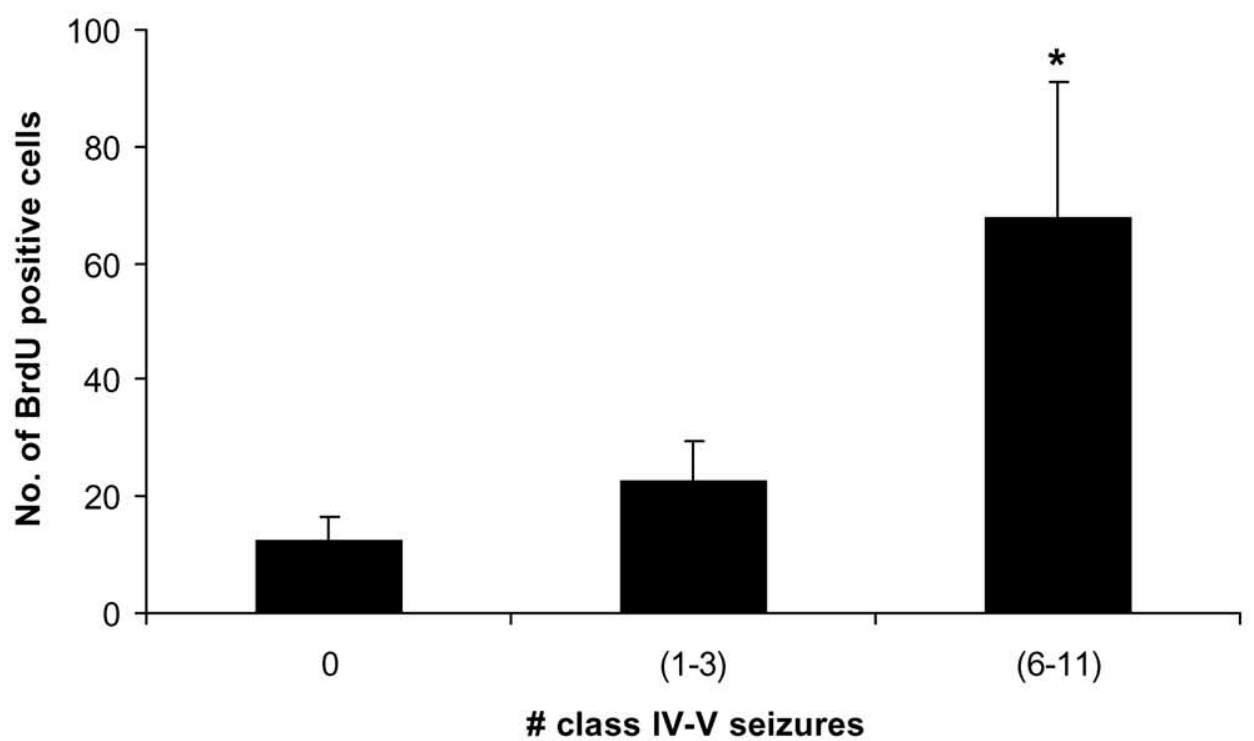

Fig. 1. BrdU-positive nuclei in the dentate gyrus of WARs with low and high frequency of GLS. (A) Animals with zero, no GLS, (B) one to three GLS and (C) six to $11 \mathrm{GLS}$ episodes. (D) Animals undergoing six to $11 \mathrm{AK}$-induced limbic seizures showed an increased number of BrdU-labeled nuclei in the DG when compared with animals with zero or one to three seizures. Labeled nuclei were counted in the GCL-hilar border (average \pm S.E.M.). * Analysis of variance followed by Student-Neumann-Keuls multiple comparison test $(P<0.05,6-11$ versus 0 and $1-3)$. Scale bar $=200 \mu \mathrm{m}$.

injection had a different aspect from those labeled 1 day after BrdU. They were larger, rounded/well-defined and usually seen isolated when compared with the not always rounded and clustered nuclei observed 1 day after BrdU injection.

\section{Electrophysiology}

Due to the transference of neuronal paroxysms from the brainstem to the forebrain, usually induced by the AK, EEG activity was monitored during the kindling protocol. We recorded EEG signals from the hippocampus and amygdala in sound-stimulated WARs and controls (WAR-sham, $\mathrm{R}$, R-sham) during every stimulus of the kindling. Fig. 5 shows EEG recordings during a typical brainstem seizure (first stimulus, ST1) and during a brainstem-induced limbic seizure (nineteenth stimulus, ST19). In the ST1, no obvious epileptic spikes were observed in both areas, even though most animals had severe tonic-clonic seizures. Low-amplitude slow oscillations (approximately $2 \mathrm{~Hz}$ ) could be seen in the hippocampus and amygdala immediately after the TCV episodes while the rats were in a catatonic-like posture and unresponsive to sensory stimuli. Although we have used a high impedance input interface in the cable head stage (Moraes et al., 2000), some movement artifacts could be observed after bouncing episodes. With the progression of kindling, amygdalar and hippocampal neurons fired hyper-synchronously and showed epileptiform paroxysms in the EEG, as seen in Fig. 5 (ST19). The discharges showed different onset times ( $8 \mathrm{~s}$ in hippocampus; $16 \mathrm{~s}$ in amygdala) and bursting frequencies $(6-9 \mathrm{~Hz}$ hippocampus; $3 \mathrm{~Hz}$ amygdala). In the hippocampus, the paroxysms occurred earlier and at a much higher rate of bursts than in the amygdala. Fig. 5 also shows a DC-shift in the hippocampus EEG that was absent in the amygdala, 


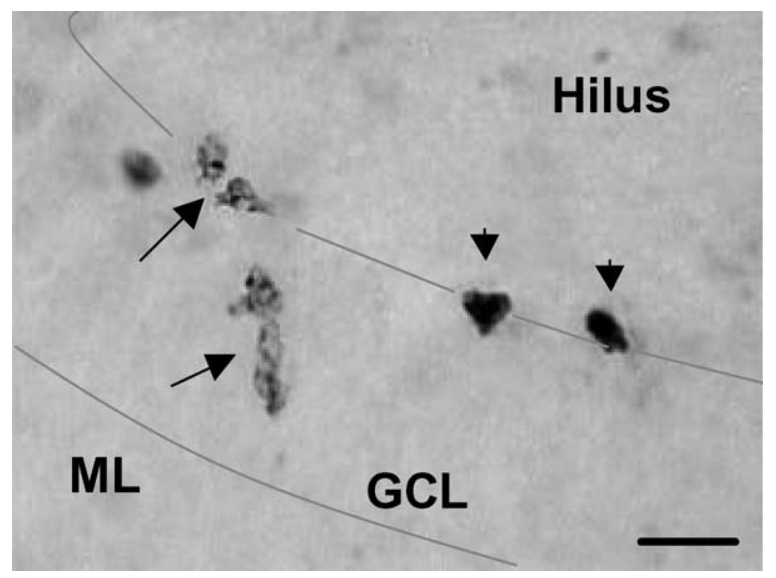

Fig. 2. BrdU-positive (arrowheads) and pyknotic nuclei (arrows) in the GCL-hilar border of the dentate gyrus from animals with six to $11 \mathrm{GLS}$. $\mathrm{ML}$, molecular layer. Scale bar $=15 \mu \mathrm{m}$.

starting after the hind-limb tonic extension (Fig. 5, ST19HLE). It persisted while the animals experienced head myoclonus (class II seizure). Animals undergoing class IV or $\mathrm{V}$ seizures had an even more intense pattern of epileptiform spikes in both areas, but with a similar EEG signature as seen in class II seizures.

\section{AK and mossy fiber sprouting}

The evaluation of hippocampal mossy fiber sprouting was carried out in sections of susceptible (WARs) and non-susceptible animals (R), 2 days and 32 days after the last sound-stimulation: R, R-sham, WAR-1d, WAR-1d sham, WAR-30d and WAR-30d sham animals. In Fig. 6 we show the Timm staining in the DG molecular layer of representative WARs. Sham-stimulated WARs-1d or WARs-30d had no seizures and did not show any significant precipitation of silver grains in the molecular layer at both time points analyzed (Fig. 6A, B). However, and interestingly, we also could not see any difference in the silver grain distribution in either WARs-1d or WARs-30d, with high number of limbic seizures (Fig. 6C, D; more than five class IV-V seizures). In two animals killed 32 days after their last seizure, we observed a subtle shadow of silver staining in the DG supra-granular layer, corresponding to one (disperse granules) in the Jolkkonen's scale, but no statistical difference was detected for the group when compared with controls. Non-susceptible $(R)$ rats also did not show any sign of silver precipitation in the molecular layer. Therefore, mossy fiber sprouting in the molecular layer of the DG does not seem to occur in WARs perfused 2 days or 1 month after kindling when compared with control rats.

\section{AK and neuronal degeneration}

Neuronal degeneration was analyzed by using FluoroJade staining, a fluorescein derivative that has high affinity for acidophilic somata and neuronal processes, indicative

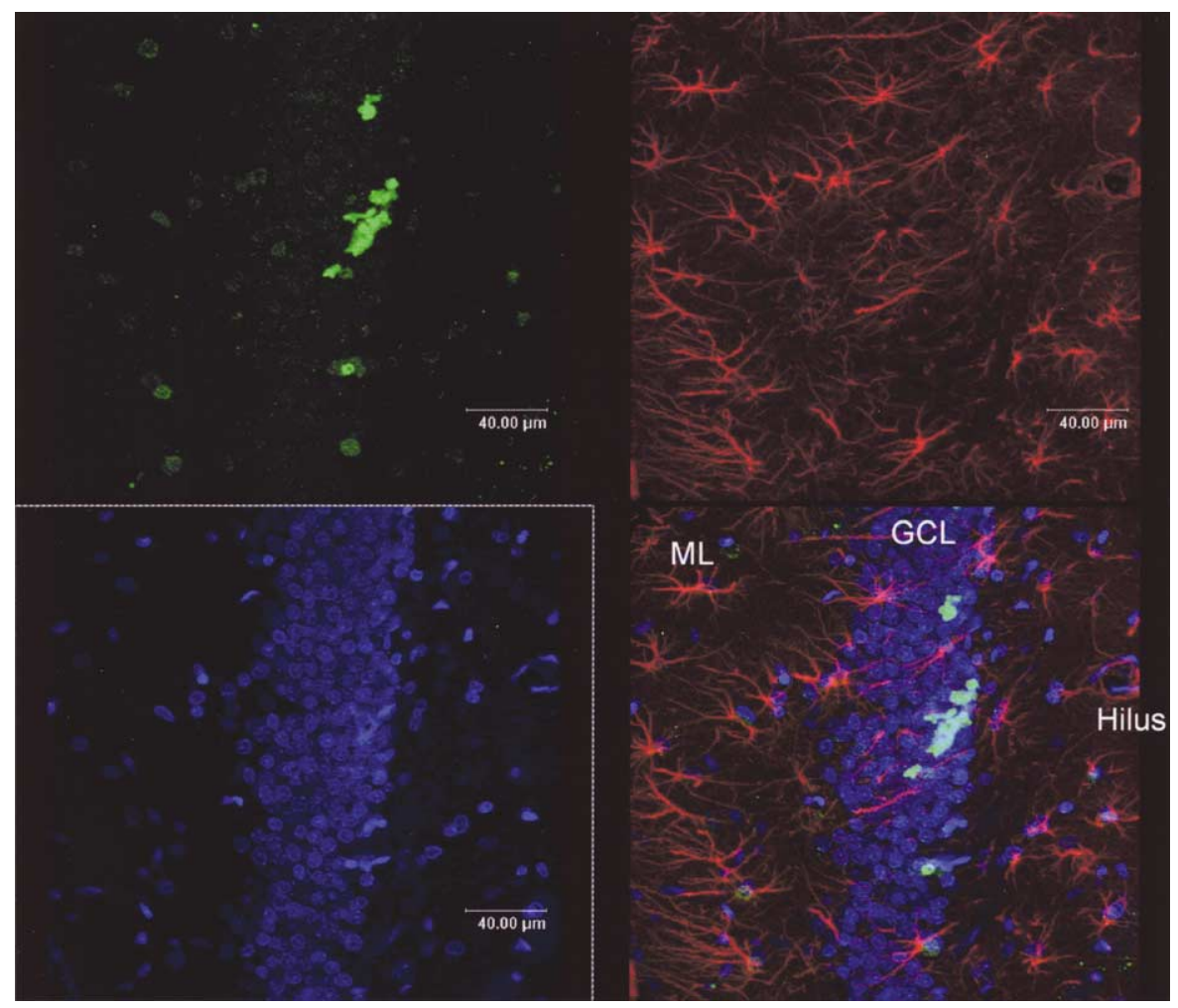

Fig. 3. Representative confocal laser scanning micrographs of the dentate gyrus of a WAR, 1 day after the last BrdU injection. In green, BrdU-positive nuclei, indicating mitotic activity, in red, GFAP-positive nuclei and in blue, nuclear counter-staining with Hoechst 33342. Clusters of BrdU-positive nuclei were mostly observed along the subgranular zone of the granule cell layer and were usually absent of GFAP co-labeling. 


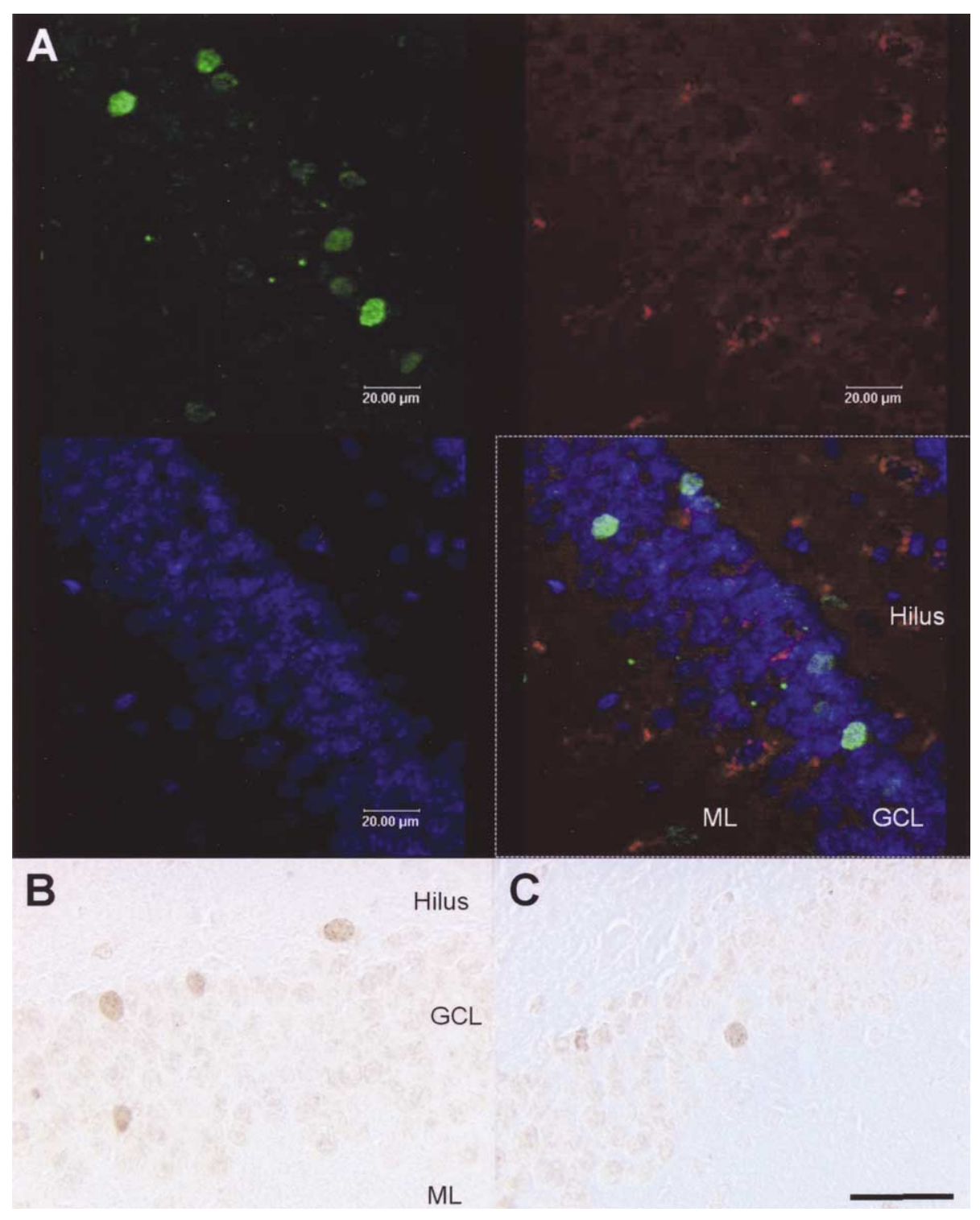

Fig. 4. Immuno-detection of BrdU incorporation in the granule cell layer of WARs, 30 days after the last BrdU injection. In A, confocal laser scanning micrographs of a BrdU/GFAP double-labeling immunofluorescence. Green represents BrdU-positive nuclei; red, GFAP-positive nuclei and blue, nuclear counter-staining with Hoechst 33342. In B and C, BrdU immunohistochemistry showing BrdU-positive nuclei in different zones along the granule cell layer. Scale bar $=60 \mu \mathrm{m}$.

of intra-cellular degeneration events (Schmued et al., 1997). A pilocarpine-treated animal was used as our positive control and showed intense Fluoro-Jade labeling of neuronal somata in the hippocampus CA1 sub-field and hilus (Fig. 7A, B), as well as in CA3, amygdala, perirhinal and cingulate cortices (data not shown), 15 days after a 90-min status epilepticus episode, as described previously (Poirier et al., 2000). However, in audiogenic kindled WARs, we did not observe any somatic labeling 2 or 32 days after their last seizure. Their tissue staining was not different from the control animals, except for some punctiform structures labeled in the retro-splenial cortex and alveus and dorsal subiculum (Fig. 7C, D) as well as, in lateral habenula and anterior thalamus (data not shown).

\section{DISCUSSION}

Our results show that GLS induced by AK in WARs are able to increase cell proliferation rate in the hippocampus, but not to promote mossy fiber sprouting in the supragranular layer of the DG nor neuronal degeneration, when evaluated by BrdU incorporation, Timm staining and Fluoro-Jade histochemistry. In addition, the newly generated cells observed in the DG do not co-localize with the astroglial marker (GFAP) and are mostly restricted to the subgranular zone in animals analyzed 1 day after the mitotic marker (BrdU) injection. BrdU-positive nuclei (but GFAP-negative) could be observed in the upper rows of the GCL, in animals 30 days after the BrdU injection, but 

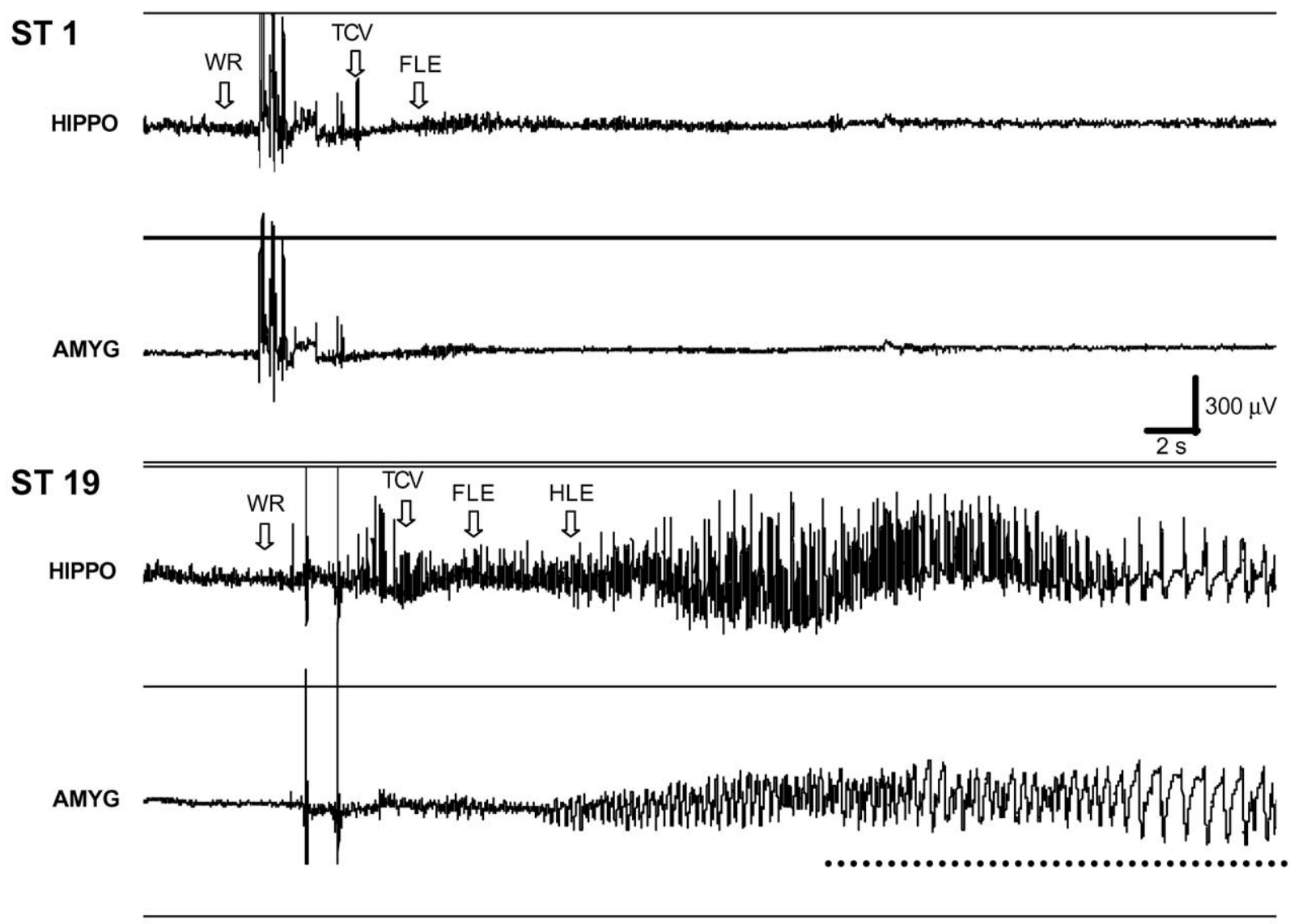

Fig. 5. EEG recordings in the hippocampus (HIPPO) and amygdala (AMYG) of WARs during the AK. In ST 1 (first stimulus), we did not observe any epileptiform spike before, during or after ictal behaviors. However, in ST 19 (stimulus 19), severe TCV and limbic seizures (head myoclonus-class II, dotted line) were accompanied by intense paroxysmal activity in the HIPPO and AMYG. The first spike bursts occurred in the HIPPO just before the TCV and were then observed in the AMYG after forelimb-hind-limb extensions. In ST1 and ST19, amplifier overloads represent movement artifacts during WR (running and bouncing) episodes. WR, wild running; TCV, tonic-clonic convulsion; FLE, forelimb extension; HLE, hindlimb extension. Recording parameters: sampling rate $500 \mathrm{~Hz}$, amplification $1000 \times$, filtering $0.1 \mathrm{~Hz}-1 \mathrm{kHz}$ and off-line filtering 1-50 Hz.

not in animals 1 day after BrdU, suggesting migration and survival of the mitotic cells after seizures. Although we have not used a neuronal specific marker to co-label the BrdU-positive nuclei, the fact that BrdU-positive/GFAPnegative and well-defined nuclei $(10 \mu \mathrm{m})$ were seen scattered throughout the GCL 30 days after the BrdU injection suggests they are newborn neurons, as it has been shown in different animal models (Gould and Cameron, 1996; Kuhn et al., 1996; Parent et al., 1997). Finally, EEG monitoring confirmed the appearance of severe epileptic discharges in the hippocampus and amygdala after repeated acoustic stimulations associated with limbic behaviors, but showed that it is not sufficient to promote mossy fiber sprouting or FluoroJade staining in susceptible animals. Higher rates of cell proliferation in the DG were observed in animals with the most intense HIPPO and AMYG epileptic spikes.

\section{Behavioral changes during the AK}

The behavioral evolution during the AK was very similar to our previous descriptions concerning the appearance of myoclonic limbic behaviors along with generalized brainstem seizures (Garcia-Cairasco et al., 1996). However, new observations were done regarding the incidence of brainstem and limbic seizures and their severity among the WARs. From a total number of 47 animals (experiment 1 and experiment 2), 84\% showed at least one TCV during the three tests of audiogenic sensitivity before starting the kindling protocol. In addition, $7 \%$ had wild running episodes and $9 \%$ did not experience any seizure, reflecting a high degree of genetic selection for the audiogenic susceptibility trait. The progression of seizure severity over 17-20 generations of inbreeding in WARs was recently demonstrated by Doretto et al. (2003). Although none of the WARs of the present work had limbic seizures during the audiogenic tests, they were present in $69 \%$ of the animals during the AK. Forty-three percent had GLS (class IV-V, Racine, 1972 ), of which $25 \%$ occurred more than five times in 28-32 sound stimuli. It demonstrates that the AK promotes, in WARs, the appearance of limbic behaviors in a significant fraction of the animals, which have similar semiology as that observed in amygdala kindling (Goddard et al., 1969) as well as in individual limbic seizures 


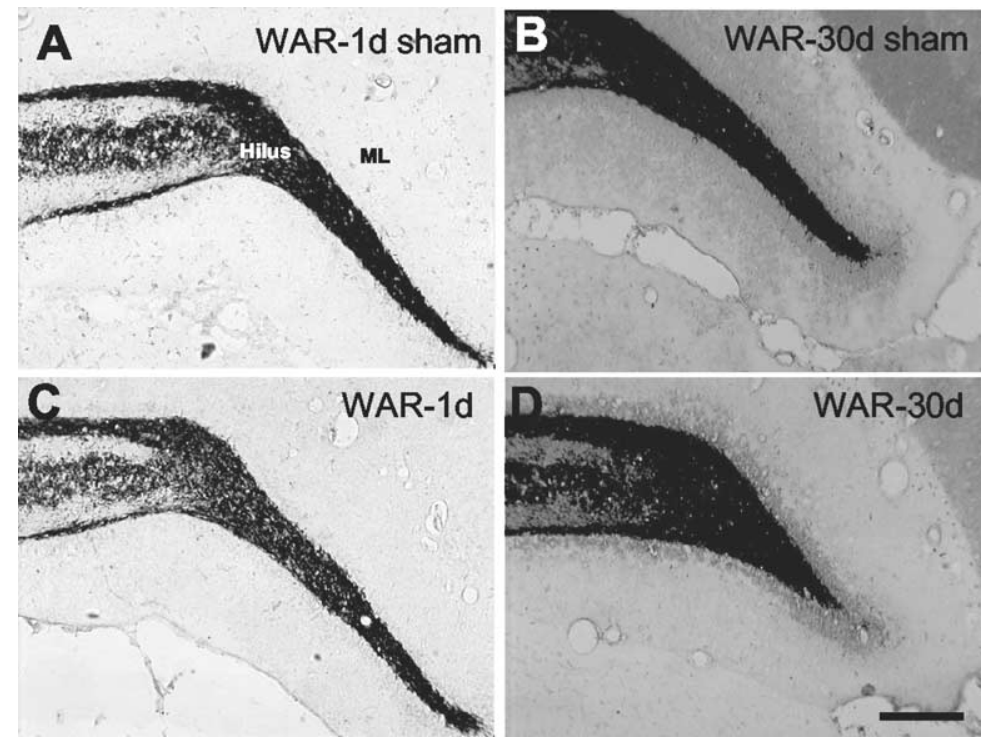

Fig. 6. Absence of mossy fiber sprouting (evaluated by Timm staining) in kindled WARs, 2 (WAR-1d) and 32 (WAR-30d) days after their last sound stimulation. Bright-field images from hippocampi of sham-stimulated (A, B) and sound-stimulated WARs (C, D). WARs-sham had no seizures after 32 kindling stimulations as well as no detectable mossy fiber sprouting. In C, the animal (WAR-1d) had 15 limbic seizures (12 class IV-V) plus 18 tonic-clonic convulsions. In D, the animal (WAR-30d) underwent two limbic plus 11 tonic-clonic seizures. Sound- stimulated and sham-stimulated non-susceptible (R) animals had similar Timm staining as WARs-sham (not shown).

of pilocarpine-induced status epilepticus (Turski et al., 1983). This is in agreement with recent data showing a progressive hyper-excitability of the amygdala after repeated audiogenic seizures in WARs (Moraes et al., 2000). It was also interesting to observe, that once the animals experienced their first limbic seizures, their ictal behavior progressed basically to two different patterns during kindling. They evolved from class II (head myoc- lonus) to class $\mathrm{V}$ (rearing and falling) seizures or persisted as class II seizures, with eventual episodes of purely tonic-clonic convulsions.

\section{AK and cell proliferation}

We observed a clear effect of the GLS induced by the AK, on the cell proliferation rate at the hippocampus. Animals

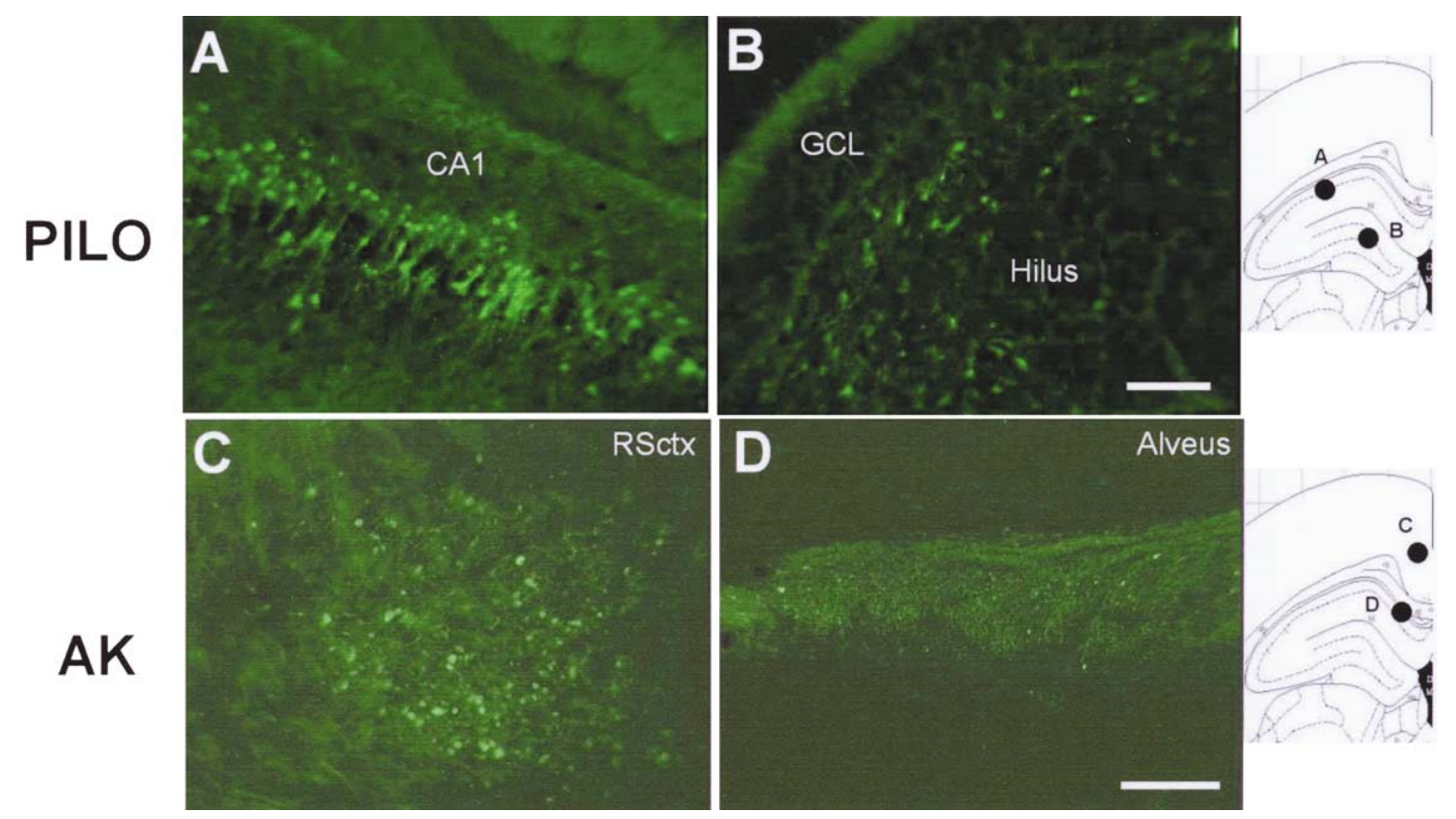

Fig. 7. Neuronal degeneration evaluated by Fluoro-Jade staining in Pilocarpine-treated (A, B) and audiogenic-kindled (C, D) animals. (A, B) Intense cytoplasmic Fluoro-Jade staining in the hippocampus CA1 and hilus of pilocarpine-treated rats, respectively, 15 days after 90 min of status epilepticus. (C, D) Punctiform, but not cytoplasmic, labeling in the retro-splenial cortex and alveus-subiculum of kindled WARs-30d. Schematic drawings, on the right, depict the specific brain regions magnified in A, B and C, D. Scale bars $=100 \mu \mathrm{m}$ (in A and B), $30 \mu \mathrm{m}$ (in C and D). 
that experienced a higher number of GLS also showed increased number of BrdU-immunoreactive cells counted in the subgranular zone of the DG, with statistically significant differences detected between animals with six to 11 class IV-V seizures and those with zero or one to three class IV-V seizures.

Similar increases in hippocampal cell proliferation have also been shown in different animal models of epilepsy that evoke intense limbic seizures such as pilocarpine and kainate status epilepticus (Parent et al., 1997; Bengzon et al., 1997; Covolan and Mello, 2000), amygdala kindling (Parent et al., 1998; Scott et al., 1998; Nakagawa et al., 2000) and electroconvulsive shock (Scott et al., 2000). However, in contrast to these models, AK initially activates brainstem areas, which if persistently stimulated, may induce epileptic activity in cortical and limbic structures (Marescaux et al., 1987; Naritoku et al., 1992; GarciaCairasco et al., 1996; Moraes et al., 2000). This specific characteristic of the paradigm enabled us to show that cell proliferation in the DG was associated with the type and number of seizures the subjects experienced. High number of brainstem seizures as well as low number of limbic seizures was not able to increase the number of BrdUlabeled cells in the hippocampus, even though hippocampal and amygdalar epileptic discharges, recorded daily in the EEG, were observed in all animals with limbic seizures and in one animal with only brainstem seizures during the kindling (data not shown). Therefore, if the mitotic activity in the DG depends on the amount of excitation reaching the hippocampus, it is plausible to think that hippocampaldemanding tasks could also modulate the production of new neurons in a physiologically functioning hippocampus.

The fact that we did not detect statistical differences between zero and one to three class IV-V seizures, but rather a tendency, suggests a possible gradual effect of the seizures on the hippocampal mitotic rate. This is in accordance with data obtained from amygdala-kindled rats, in which an increased number of BrdU-labeled nuclei was observed in animals with nine to 10 and 19-20 class IV-V seizures when compared with controls with zero and four to six class IV-V seizures (Parent et al., 1998). Nakagawa et al. (2000) have shown a similar effect of the number and severity of seizures on the abundance of BrdU-labeled cells in the DG. However, both groups also found unexpected effects on BrdU labeling in some animals experiencing the most elevated number of seizures.

Considering the identity of the mitotic cells, fluorescent double labeling with GFAP and BrdU antibodies, 1 day after BrdU injection, revealed that essentially all BrdUpositive cells lying in the subgranular zone did not colocalize with GFAP-positive staining, suggesting that at least part of these cells had neuronal phenotype (Fig. 3). In fact, 30 days after the last BrdU injection, we did not see any clusters of BrdU-positive cells, but rather we observed BrdU-positive/GFAP-negative nuclei placed in the middle and upper rows of the GCL (Fig. 4). These nuclei were rounded and compact (see Fig. 4A-C) contrasting to large and invaginated nuclei observed in chandelier and basket interneurons present in the GCL (Freund and Buzsaki,
1996). Although chandelier cells may be found within or immediately adjacent to the GCL, basket cells are often found in the hilar border. Therefore, together with previous studies showing similar distribution of BrdU-labeled cells 1 day and 4 weeks after BrdU injections, we suggest that the proliferating cells generated after AK-induced limbic seizures could differentiate and become incorporated in the GCL as new neurons. However, it has still to be shown how many of these cells become glia, granule cells or interneurons.

Although we do not know the precise mechanisms involved in the increase of hippocampal cell proliferation following limbic seizures, some factors are well known to affect normal adult neurogenesis in rats and could possibly be implicated during AK: NMDA neurotransmission, stress and neurotrophins (Cameron et al., 1998; Lindvall et al., 1994). The NMDA transmission and the glucocorticoid release during stressful events are known to have inhibitory effects on hippocampal neurogenesis. On the other hand, the expression and release of hippocampal neurotrophins after seizures have been shown to increase in different epilepsy models and to promote mossy fiber neosynaptogenesis (Gall, 1993; Lindvall et al., 1994). So, it is reasonable to think that during $\mathrm{AK}$, more frequent and intense limbic seizures induce an increased release of neurotrophins (e.g. BDNF, NGF and NT-3) in the hippocampus, which ultimately would promote the activation of granule cell progenitors. NMDA receptor activation and stress should attenuate this effect. Actually, it is still unclear how these and other factors sum together to yield a net increase in hippocampal neurogenesis after seizures. Ictal events in neonatal brains seem to have a different modulation on the granule cell proliferation (McCabe et al., 2001).

\section{Mossy fiber sprouting in the supragranular layer of the DG}

Timm histochemistry was used to evaluate mossy fiber sprouting in the supragranular layer of the DG of animals 2 and 32 days after their last AK stimulation. In Fig. 6, we can see a complete absence of silver granule intensification in the supragranular layer of representative WARs when compared with controls. The highest Timm scores observed in kindled WARs were evaluated to be one (sparse granules along the supragranular layer). The same was observed in sound-stimulated $R$ animals. As a result, our data show that AK did not promote mossy fiber sprouting in the supragranular layer of DG in WARs, as previously reported (Garcia-Cairasco et al., 1996).

The absence of mossy fiber sprouting after the AK may be related to the particular characteristics of the AK paradigm, the number/severity of limbic seizures and/or the time for tissue analysis after the insult. During the AK, the epileptic circuitry is expanded from mesencephalic to forebrain limbic areas and in fact, it is different from what is observed during amygdala and hippocampal kindling (Goddard et al., 1969; Racine, 1972, Lerner-Natoli et al., $1984 a, b)$, sometimes associated with mossy fiber sprouting (Represa et al., 1989; Cavazos et al., 1991). It is 
possible however that an even higher number of severe limbic seizures than those showed in our study is necessary to promote a significant and measurable mossy fiber sprouting. Previous data from our laboratory have shown that, even 160 days after 80 AK-stimulations, an additional 16 stimuli of amygdala kindling are insufficient to induce mossy fiber sprouting in the supragranular layer of the DG of WARs (Galvis-Alonso et al., 2000). However, it is possible to observe increased optical density in the Timmstained amygdala, perirhinal cortex and piriform cortex in kindled WARs (Garcia-Cairasco et al., 1996; GalvisAlonso et al., 2000). Similar absence of mossy fiber sprouting has also been shown in the amygdala-kindling model (Mohapel et al., 2000, Osawa et al., 2001), sometimes with no evidence of neuronal loss (Osawa et al., 2001). In addition, Longo and Mello (1997, 1998) have demonstrated that mossy fiber sprouting induced by pilocarpine can be blocked by cycloheximide without blocking spontaneous recurrent seizures. However, there is still debate on the relationship between pilocarpine-induced mossy fiber sprouting and spontaneous seizures (Williams et al., 2002). Since WARs do not seem to show spontaneous seizures, the increasing severity of seizures during AK does not necessarily need to be associated with mossy fiber sprouting.

Therefore, our data support earlier studies showing that mossy fiber sprouting is not necessarily associated with repetitively induced limbic seizures and we hypothesize that other mechanisms could be involved in the limbic hyper-excitability after the AK, such as increased hippocampal neurogenesis and/or an unbalance in the glutamatergic-GABAergic neurotransmission in the midbrain projections toward the hippocampus and amygdala (Ribak and Morin, 1995; for a review on brainstem-limbic circuitry in kindled audiogenic seizures, see Garcia-Cairasco, 2002). Furthermore, a very recent study by Li et al. (2002) shows that, by using synaptophysin as a marker of seizure-induced synaptogenesis, it is possible to detect different territories of plasticity well beyond the hippocampus.

\section{Cell death}

Fluoro-Jade histochemistry has been suggested to specifically label degenerating neurons as demonstrated by costaining of brain tissues using Fluoro-Jade and GFAP or NeuN (Schmued et al., 1997). In addition, it seems to have chemical affinity for degenerating neurons, in contrast to the dark-cell method that can label "suffering cells," not all necessarily prone to die (Toth et al., 1998). At least for the pilocarpine model, the best labeling window for FluoroJade occurs between $24 \mathrm{~h}$ and 7 days after the insult (Poirier et al., 2000). For the AK paradigm this is the first time Fluoro-Jade has been used to analyze neuronal degeneration and represents an initial effort to search for cell loss in this model of limbic seizures.

Our results show that our positive control, from a pilocarpine status epilepticus animal (1.5 h S.E., perfused $24 \mathrm{~h}$ after the S.E.), had a very clear Fluoro-Jade labeling. An intense and abundant number of stained cells were observed in limbic areas such as the hippocampus CA1, hilus, amygdala and perirhinal cortex, with cellular distribution detected in the soma and the dendrites of pyramidal cells (Fig. 7A, B).

Although some pyknotic nuclei were found near BrdUlabeled cells in the sub-granular zone, it is likely to reflect a turnover of mitotic cells rather than a cell death event triggered by seizures. Moreover, they were always adjacent to the GCL. Cell degeneration has been observed to be associated with seizure-induced neurogenesis in limbic structures (Bengzon et al., 1997; Covolan et al., 2000).

However, we were not able to identify somatic labeling of Fluoro-Jade in both intact (1 day) or implanted (1 day/30 days) audiogenic kindled WARs. No sign of cellular degeneration was detected in the thalamus, hypothalamus, hippocampus, amygdala, somatosensory cortex, perirhinal cortex, piriform cortex and substantia nigra (data not shown).

These results are in accordance with previous findings showing that hippocampal or amygdalar kindling does not promote neuronal degeneration (Bertram and Lothman, 1993; Khurgel et al., 1995; Osawa et al., 2001). Particularly, Bertram and Lothman (1993) showed that 1500 intermittent kindled seizures did not affect the number of neurons in the DG compared with controls without stimulation. In contrast, neuronal loss has been reported in other kindling models (Cavazos and Sutula, 1990; Cavazos et al., 1994; Mody, 1999).

A possible explanation for the absence of Fluoro-Jade staining in the AK model could be the fact that it promotes a more subtle activation of limbic structures during each sound stimulation episode. Although the animals can reach class $V$ seizures, they occur with a different kinetics and in a very distinct seizure context, along with wild running and generalized tonic seizures (Garcia-Cairasco et al., 1996). Nevertheless, in some implanted animals, we observed a punctiform and fibrous labeling in the retrosplenial cortex and alveus/dorsal subiculum (Fig. 7C, D), which were never associated with the electrode tract. Notably, these areas have some direct or indirect relation to limbic structures activated during limbic seizures (Miller et al., 1987; Covolan and Mello, 2000). Schmued et al. (1997) working in other models have suggested that similar labeling pattern could represent degenerating axonal terminals. This labeling pattern was not observed in control animals exposed to the same experimental setup.

Other possible explanations for the absence of FluoroJade staining in the present study would be the occurrence of cell death in a different time window from those analyzed here, or a neuroprotective effect of repeated seizures during kindling (Kelly and Mclntyre, 1994). Because we carried out the Fluoro-Jade staining for the cumulative effect of several seizures with an interval of at least $48 \mathrm{~h}$ after the last seizure, further experiments should be designed to determine the best Fluoro-Jade window for AK seizures, not only after the last seizure but also during the kindling protocol. Additional estimative of neuronal density in other brain areas would be helpful to understand eventual degenerative or protective effects of AK. 


\section{Electrophysiology, seizures and cellular responses}

Implanted animals were simultaneously recorded from amygdalar and hippocampal electrodes during all stimulation episodes during the AK protocol (16 days; $2 \times /$ day). Our main finding shows that paroxysmic activity in the hippocampus and amygdala was not always correlated with limbic seizures and the increase in number of BrdUlabeled nuclei in the GCL; epileptic discharges and high mitotic rate were not synonyms. In contrast, high levels of BrdU incorporation were observed only in animals with frequent and severe behavioral limbic seizures. These corresponded to a very high frequency of epileptic discharges in amygdala and hippocampus during the kindling. No correlation was observed between EEG paroxysms and Timm or Fluoro-Jade staining.

We could observe remarkable changes in the EEG activity of the amygdala and hippocampus after repetitive sound stimulations in all animals showing limbic seizures (Fig. 5). However, these high amplitude poly-spike bursts were also observed in one animal that never expressed limbic behaviors during the AK (data not shown), indicating that electrographic limbic seizures could also occur without their behavioral correlates. Previous reports have also shown hippocampus or amygdala paroxysmal activity intensely occurring during the AK (Hirsh et al., 1994; Moraes et al., 2000).

Some neuronal projections could account for this midbrain-to-forebrain electrographic seizure propagation. The first one is the projection from the inferior colliculus to the amygdala, via the auditory thalamus. Collicular sensitization could, indirectly, hyper-stimulate the amygdala and, due to its low-threshold for seizures, induce limbic myoclonus behaviors. Hirsh et al. (1997) have shown that amygdalar, but not hippocampal, lidocaine injections abolish these behaviors during the AK, demonstrating the role of amygdala in the expression of limbic behaviors in the AK. The second candidate could be the connection between the pontine reticular formation to the hippocampus. It is known that this brainstem structure is critical to the motor output of the audiogenic seizures and has a significant increase in its neuronal activity during these seizures (Faingold, 1999). Furthermore, it has been shown that electrical stimulation or lesions in the nucleus reticularis pontis oralis can induce or extinguish the hippocampal $\theta$ wave oscillation, indicating its involvement in the hippocampal neuronal modulation (Vertes, 1981). For further information on this complex circuitry, insights on acousticmotor and acoustic-limbic anatomical and functional interactions during the progression from acute to kindled audiogenic seizures, mainly in WARs, were recently presented by Garcia-Cairasco (2002).

\section{CONCLUSION}

In our study we have shown that AK evokes intense paroxysmic electrographic activity simultaneously, in the hippocampus and amygdala, inducing an increase in hippocampal cell proliferation in animals with high number of GLS. The newly generated cells did not co-localize with the astroglial marker and could be found in different levels of this layer, suggesting that these cells proliferate, migrate and become part of the GCL, as it has been observed for granule neurons. However, the plastic responses triggered by the repetitive sound stimulations were not sufficient to promote mossy fiber sprouting in the supra-granular layer of the DG. We also could not detect Fluoro-Jade labeling in the major forebrain areas analyzed (cortex, hippocampus, amygdala and thalamus), suggesting a possible lack of neuronal degeneration in the AK paradigm. Together, these findings bring an important contribution to the understanding of how repetitive seizure episodes affect the brain functioning during adulthood.

Acknowledgements-Financial support, FAPESP (grants 99/ 06756-0 and 99/06586-8), CNPq (grant 521697/96-4), CAPESPROAP, PADCT (grant BIO-01/94-01), PRONEX (grant 357/96) to NGC. Special thanks to Dr. L. E. A. M. Mello and Dr. L. Covolan for their help and technical advice with the BrdU immunohistochemistry. To Dr. Maria Celia Jamur, Dr. Constance Olivier and Marcia Graeff for their kind assistance on the immunofluorescence and confocal experiments. To Dr. M. F. D. Moraes for his advice with the EEG studies. To J. A. C. Oliveira and F. Del Vecchio, for their technical help with the WAR strain, behavioral procedures and stereotaxic surgeries. N.G.-C. and R.N.R.-P. were recipients of CNPq-Brazil Research Fellowships.

\section{REFERENCES}

Amaral GD, Witter MP (1994) Hippocampal formation. In: The rat nervous system, 2nd edition (Paxinos G, ed), pp 443-493. San Diego: Academic Press.

Babb TL, Kupfer WR, Pretorius JK, Crandall PH (1991) Synaptic reorganization by mossy fibers in human epileptic fascia dentata. Neuroscience 42:351-363.

Ben-Ari Y (1985) Limbic seizure and brain damage produced by kainic acid: mechanisms and relevance to human temporal lobe epilepsy. Neuroscience 14:375-403.

Bengzon J, Kokaia Z, Elmér E, Nanobashvili A, Kokaia M, Lindvall O (1997) Apoptosis and proliferation of dentate gyrus neurons after single and intermittent limbic seizures. Proc Natl Acad Sci USA 94:10432-10437.

Bertram EH, Lothman EW (1993) Morphometric effects of intermittent kindled seizures and limbic status epilepticus in the dentate gyrus of the rat. Brain Res 603:25-31.

Lothman EH, Cornett EW (1993) Morphometric effects of intermittent kindled seizures and limbic status epilepticus in the denote gyrus of the rat. Brain Res 603:25-31.

Cameron HA, Tanapat P, Gould E (1998) Adrenal steroids and Nmethyl-D-aspartate receptor activation regulate neurogenesis in the dentate gyrus of adult rats through a common pathway. Neuroscience 82:349-354.

Cavazos JE, Das I, Sutula TP (1994) Neuronal loss induced in limbic pathways by kindling: evidence for induction of hippocampal sclerosis by repeated brief seizures. J Neurosci 14:3106-3121.

Cavazos JE, Golari G, Sutula TP (1991) Mossy fiber synaptic reorganization induced by kindling: time course of development, progression and development. J Neurosci 11:2795-2803.

Cavazos JE, Sutula TP (1990) Progressive neuronal loss induced by kindling: a possible mechanism for mossy fiber synaptic reorganization and hippocampal sclerosis. Brain Res 527:1-6.

Clough RW, Eells JB, Browning RA, Jobe P (1997) Seizures and proto-oncogene expression of c-fos in the brain of adult genetically epilepsy-prone rats. Exp Neurol 146:341-353.

Covolan L, Mello LEAM (2000) Temporal profile of neuronal injury 
following pilocarpine or kainic acid-induced status epilepticus. Epilepsy Res 39:133-152.

Covolan L, Ribeiro LT, Longo BM, Mello LE (2000) Cell damage and neurogenesis in the dentate granule cell layer of adult rats after pilocarpine- or kainite-induced status epilepticus. Hippocampus 10: 169-180.

Danscher G (1981) Histochemical demonstration of heavy metals. Histochemistry 71:1-16.

Doretto MC, Fonseca CG, Lobo RB, Terra VC, Oliveira JAC, GarciaCairasco N (2003) Quantitative study of the response to genetic selection of the Wistar audiogenic rat strain (WAR). Behav Genet 33:33-41.

Faingold CL (1999) Neuronal networks in the genetically epilepsyprone rat. Adv Neurol 79:311-321.

Freund TF, Buzsaki G (1996) Interneurons of the hippocampus. Hippocampus 6:347-470.

Gall CM (1993) Seizure induced changes in neurotrophin expression: implications for epilepsy. Exp Neurol 124:150-166.

Galvis-Alonso OY, Oliveira JAC, Gracia-Cairasco N (2000) Audiogenic kindling induces limbic epileptogenic activity associated with plastic changes and neuroprotection. Soc Neurosci Abstr 26:228.

Garcia-Cairasco N, Wakamatsu H, Oliveira JAC, Gomes ELT, Del Bel EA, Mello LEAM (1996) Neuroethological and morphological (NeoTimm staining) correlates of limbic recruitment during the development of audiogenic kindling in seizure susceptible Wistar rats. Epilepsy Res 26:177-192.

Garcia-Cairasco N (2002) A critical review on the participation of inferior colliculus in acoustic-motor and acoustic-limbic networks involved in the expression of acute and kindled audiogenic seizures. Hear Res 168:208-222.

Goddard GV, McIntyre DC, Leech CK (1969) A permanent change in brain function resulting from daily electrical stimulation. Exp Neurol 25:295-330.

Gould E, Cameron HA (1996) Regulation of neural birth, migration and death in the rat dentate gyrus. Dev Neurosci 18:22-35.

Hirsh E, Danober L, Simler S, Pereira de Vasconcelos A, Maton B, Nehlig A, Marescaux C, Vergnes M (1997) The amygdala is critical for seizure propagation from brainstem to forebrain. Neuroscience 77:975-984.

Hirsh E, Vergnes M, Simler S, Maton B, Nehlig A, Marescaux C (1994) Propagation of generalized seizures from brainstem to forebrain networks. In: Idiopathic generalized epilepsies: clinical, experimental and genetic aspects (Malafose A, Genton P, Hirsh E, Marescaux CD, Bernasconi R, eds), pp 415-424. London: John Libbey.

Jolkkonen J, Jolkkonen E, Pitkanen A (1997) Seizure-induced damage to somatostatin-immunoreactive neurons in the rat hippocampus is regulated by fimbria-fornix transection. Exp Neurol 145:141-153.

Keily ME, McIntyre DC (1994) Hippocampal kindling protects several structures from the neuronal damage resulting from kainic acidinduced status epilepticus. Brain Res 634:245-256.

Kesner RP (1966) Subcortical mechanisms of audiogenic seizures. Exp Neurol 15:192-205.

Khurgel M, Switzer RC 3rd, Teskey GC, Spiller AE, Racine RJ, Ivy GO (1995) Activation of astrocytes during epileptogenesis in the absence of neuronal degeneration. Neurobiol Dis 2:23-35.

Kuhn HG, Dickinson-Anson H, Gage FH (1996) Neurogenesis in the dentate gyrus of the adult rat: age-related decrease of neuronal progenitor proliferation. J Neurosci 16:2027-2033.

Lerner-Natoli M, Rondouin G, Baldy-Moulinier M (1984a) Evolution of wet dog shakes during kindling in rats: comparison between hippocampal and amygdala kindling. Exp Neurol 83:1-12.

Lerner-Natoli M, Rondouin G, Baldy-Moulinier M (1984b) Hippocampal kindling in the rat: intrastructural differences. J Neurosci Res 12: 101-111.

Li S, Reinprecht I, Fahnestock M, Racine RJ (2002) Activity-dependent changes in synaptophysin immunoreactivity in hippocampus, piriform cortex and entorhinal cortex of the rat. Neuroscience 115: $1221-1229$
Lindvall O, Kokaia Z, Bengzon J, Elmer E, Kokaia M (1994) Neurotrophins and brain insults. Trends Neurosci 17:490-496.

Longo BM, Mello LEAM (1997) Blockade of pilocarpine- or kainiteinduced mossy fiber sprouting by cycloheximide does not prevent subsequent epileptogenesis in rats. Neurosci Lett 226:163-166.

Longo BM, Mello LEAM (1998) Supragranular mossy fiber sprouting is not necessary for spontaneous seizures in the intrahippocampal kainate model of epilepsy in the rat. Epilepsy Res 32:171-182.

Marescaux CM, Vergnes M, Kiesmann M, Depaulis G, Michletti G, Warter JM (1987) Kindling of audiogenic seizures in Wistar rats: an EEG study. Exp Neurol 97160-97168.

McCabe BK, Silveira DC, Cilio MR, Cha BH, Liu X, Sogawa Y, Holmes GL (2001) Reduced neurogenesis after neonatal seizures. J Neurosci 21:2094-2103.

Miller JW, McKeon AC, Ferrendelli JA (1987) Functional anatomy of pentylenetetrazol and electroshock seizures in the rat brainstem. Ann Neurol 22:615-621.

Mody I (1999) Synaptic plasticity in kindling. Adv Neurol 79:631-643.

Moraes MF, Galvis-Alonso OY, Garcia Cairasco N (2000) Audiogenic kindling in the Wistar rat: a potential model for recruitment of limbic structures. Epilepsy Res 39:251-259.

Mohapel P, Armitage LL, Gilbert TH, Hannesson DK, Teskey GC, Corcoran ME (2000) Mossy fiber sprouting is dissociated from kindling of generalized seizures in the guinea-pig. Neuroreport 11:2897-2901

Nakagawa E, Aimi Y, Yasuhara O, Tooyama I, Shimada M, McGeer PL, Kimura $\mathrm{H}$ (2000) Enhancement of progenitor cell division in the dentate gyrus triggered by initial limbic seizures in rat models of epilepsy. Epilepsia 41:10-18.

Naritoku DK, Mecozzi LB, Aiello MT, Faingold CL (1992) Repetition of audiogenic seizures in genetically epilepsy-prone rats induces cortical epileptiform activity and additional seizure behaviors. Exp Neurol 115:317-324.

N'Gouemo P, Faingold CL (1996) Repetitive audiogenic seizures cause an increased acoustic response in inferior colliculus neurons and additional convulsive behaviours in the genetically-epilepsy prone rat. Brain Res 710:92-96.

N'Gouemo P, Faingold CL (1997) Audiogenic kindling increases neuronal responses to acoustic stimuli in neurons of the medial geniculate body of the genetically epilepsy-prone rat. Brain Res 761: 217-224.

Nowakowski RS, Lewin SB, Miller MW (1989) Bromodeoxyuridine immunohistochemical determination of the lengths of the cell cycle and the DNA-synthetic phase for an anatomically defined population. J Neurocytol 18:311-318.

Osawa M, Uemura S, Kimura H, Sato M (2001) Amygdala kindling develops without mossy fiber sprouting and hippocampal neuronal degeneration in rats. Psychiatry Clin Neurosci 55:549-557.

Parent JM, Janumpali S, McNamara J, Lowenstein DH (1998) Increased dentate granule cell neurogenesis following amygdala kindling in the adult rat. Neurosci Lett 247:9-12.

Parent JM, Yu TW, Leibowitz RT, Geshwind DH, Sloviter RS, Lowenstein DH (1997) Dentate granule cell neurogenesis is increased by seizures and contributes to aberrant network reorganization in the adult rat hippocampus. J Neurosci 17:3727-3738.

Paxinos G, Watson C (1997) The rat brain in stereotaxic coordinates, third edition. San Diego, CA: Academic Press.

Pereira R, Garcia-Cairasco N (2000) Increased granule cell proliferation in a model of audiogenic kindling. Epilepsia 41 (suppl 7):46.

Poirier JL, Capek R, De Koninck Y (2000) Differential progression of dark neuron and Fluoro-Jade labelling in the rat hippocampus following pilocarpine-induced status epilepticus. Neuroscience 97: $59-68$.

Racine RJ (1972) Modification of seizure activity by electrical stimulation: II. Motor seizure. Electroencephal Clin Neurophysiol 32:281-294.

Represa A, Le Gall La Salle G, Ben-Ari Y (1989) Hippocampal plas- 
ticity in the kindling model of epilepsy in rats. Neurosci Lett 99:345350.

Ribak C, Morin CL (1995) The role of the inferior colliculus in a genetic model of audiogenic seizures. Anat Embryol 191:279-295.

Schmued LC, Albertson C, Slikker W (1997) Fluoro-Jade: a novel fluorochrome for the sensitive and reliable histochemical localization of neuronal degeneration. Brain Res 751:37-46.

Scott BW, Wang S, Burnham WM, De Boni U, Wojtowicz JM (1998) Kindling-induced neurogenesis in the dentate gyrus of the rat. Neurosci Lett 248:73-76.

Scott BW, Wojtowicz JM, Burnham WM (2000) Neurogenesis in the dentate gyrus of the rat following electroconvulsive shock seizures. Exp Neurol 165:231-236.

Simler S, Vergnes M, Marescaux C (1999) Spatial and temporal relationships between c-fos expression and kindling of audiogenic seizures in Wistar rats. Exp Neurol 157:106-119.

Simler S, Hirsch E, Danober L, Motte J, Vergnes M, Marescaux C (1994) C-fos expression after single and kindled audiogenic seizures in Wistar rats. Neurosci Lett 75:58-62.
Sutula TP (1991) Reactive changes in epilepsy: cell death and axon sprouting induced by kindling. Epilepsy Res 10:62-70.

Tauck DL, Nadler JV (1985) Evidence of functional mossy fiber sprouting in the hippocampal formation of kainic acid-treated rats. J Neurosci 5:1016-1022.

Toth Z, Yan XX, Hafgtoglou S, Ribak CE, Baram TZ (1998) Seizureinduced neuronal injury: vulnerability to febrile seizures in an immature rat model. J Neurosci 18:4285-4294.

Turski WA, Cavalheiro EA, Schwarz M, Czuczwar SJ, Kleinrok Z, Turski L (1983) Limbic seizures produced by pilocarpine in rats: a behavioral, electroencephalographic and neuropathological study. Behav Brain Res 9:315-335.

Vertes RP (1981) An analysis of ascending brain stem systems involved in hippocampal synchronization and desynchronization. J Neurophysiol 46:1140-1159.

Williams PA, Wuarin JP, Dou P, Ferraro DJ, Dudek FE (2002) Reassessment of the effects of cycloheximide on mossy fiber sprouting and epileptogenesis in the pilocarpine model of temporal lobe epilepsy. J Neurophysiol 88:2075-2087. 